\title{
El control de la agenda mediática en campaña electoral El caso de las elecciones generales españolas de 2004
}

\author{
Dr. Francisco Javier Paniagua Rojano \\ Dr. Bernardo J. Gómez Calderón \\ Profesores del Departamento de Periodismo de la Universidad de Málaga
}

\section{Resumen}

La información periodística en periodo electoral constituye uno de los más claros ejemplos del modo en que la agenda de los medios y la de los ciudadanos interaccionan, y de cómo unos $y$ otros condicionan las cuestiones sobre las que se debate en la esfera pública. Para analizar esta vertiente del discurso de los medios, la hipótesis de la "agenda-setting", enunciada en 1972 por McCombs y Shaw, constituye un instrumento heurístico de indudable eficacia, capaz de orientar al investigador cuando de definir el origen de los asuntos que movilizan a la opinión pública se trata. En este artículo se define el comportamiento de todos los actores implicados en la comunicación política a partir del modelo de la "agenda-setting", aplicándolo a la campaña electoral correspondiente a las elecciones generales celebradas en España en marzo de 2004.

\section{Abstract}

The journalistic information in electoral period constitutes one of the clearest examples of the way that "mass media" agenda and citizens' agenda interact, and how both elements condition the questions about people struggle. In order to analyze this slope of the media action, the hypothesis of the "agenda-setting"-enunciated in 1972 by McCombs and Shaw- is an effective heuristic instrument, which orients the investigator when he has to define the origin of the subjects that mobilize to the Public Opinion. In this article, authors define the behaviour of all actors implied in the political communication using the "agenda-setting" theory, and illustrate their conclusions with the electoral campaign for the general elections celebrated in Spain in 2004.

Palabras clave: comunicación política, "agenda-setting", campañas electorales.

Key words: political communication, "agenda-setting", electoral campaigns 


\section{ANTECEDENTES. LA "AGENDA-SETTING"}

a teoría de la "agenda-setting" ha constituido un importante paso en la investigación sobre los efectos de la comunicación de masas. El supuesto básico del que parte es que los medios son efectivos en la medida en que consiguen transferir a la audiencia la importancia que otorgan a los temas a los que dan cobertura ${ }^{3}$.

La teoría de la "agenda-setting" fue propuesta por Maxwell McCombs y Donald Shaw en el año 1972. Estos dos autores plantearon una metodología cuantitativa, la correlación estadística, para analizar cuál es el nexo entre los temas que los medios consideran importantes -agenda de los medios- y las cuestiones a las que los ciudadanos prestan más atención -agenda del público-.

Su estudio consistió en un análisis de la cobertura que cinco diarios, dos revistas de información general y dos cadenas de televisión norteamericanos dieron a la campaña electoral de 1968 en Carolina del Norte, a partir del cual definieron la agenda predominante de los medios de comunicación.

Al mismo tiempo, se realizó un sondeo entre los ciudadanos del mismo estado, usando la pregunta de Gallup ¿Cuál piensa usted que es el problema más importante que ha de afrontar el país?, de cuya respuesta se extrajo la agenda de los sujetos receptores. Utilizando la correlación estadística, McCombs y Shaw comprobaron que existía un estrecho vínculo entre la agenda de los medios y la de los ciudadanos, es decir, entre los temas a los que los periodistas otorgaban relevancia y aquellos que la gente consideraba más importantes.

Así se llegó a la conclusión de que los medios logran trasladar a la audiencia la prioridad que ellos mismos conceden a las cuestiones sobre las que informan u opinan. Sirviéndose de la frase de Cohen quizá los medios de comunicación no dicen a la gente qué hay que pensar, pero sí establecen la agenda de los temas sobre los que hay que pensar, McCombs y Shaw concluyeron que prensa, radio y televisión establecen la agenda del público (de ahí el nombre de "agenda-setting"), ya que consiguen transferirles la jerarquía temática por ellos establecida. De esta manera, si los medios dan prioridad al terrorismo o a la corrupción, estos serán los asuntos sobre los que los ciudadanos debatan. Esto implica que los receptores son vulnerables a los efectos de los medios o, dicho de manera más neutral, sensibles al "establecimiento de la agenda" que éstos ejercen ${ }^{4}$.

Desde 1972 y hasta nuestros días, se han emprendido numerosas investigaciones con el objeto de perfeccionar esta teoría, añadiendo hallazgos de interés que enriquecen el análisis del estudio de los efectos de los medios. Por ejemplo, se ha constatado que los ciudadanos acusan más los efectos de la "agenda-setting"

\footnotetext{
${ }^{3}$ Véase COHEN, Bernard: The Press and Foreing Policy. Princeton University Press, Princeton, 1963.

${ }^{4}$ Véase McCOMBS, Maxwell y SHAW, Donald: The Emergence of American Political Issues: The Agenda-Setting Function of the Press, Minnesota: West Publishing Co., Saint Paul, 1977.
} 
cuando precisan de orientación, tal y como ocurrió el 11 de marzo de 2004 con los atentados terroristas de Madrid: los españoles necesitaban información y recurrieron a todos los medios posibles, sin descartar Internet y los teléfonos móviles.

Por otro lado, el ciudadano acusa también la prioridad de temas en términos de espacio y tiempo de dedicación, como afirma Funkhouser ${ }^{5}$. Para este autor norteamericano, la prensa y la televisión tienen diferentes efectos por lo que al establecimiento de la agenda se refiere. Por ejemplo, en una campaña electoral, los diarios resultan más efectivos durante los primeros días, si bien conforme se acerca la jornada de votación, es la televisión el medio que logra establecer la agenda del público, como señalan Benton y Fraizier $^{6}$, porque el efecto audiovisual parece que se recuerda más. Sin embargo, los medios impresos son más eficaces a la hora de establecer la agenda de temas en los niveles de conocimiento más profundos.

Posteriormente, y para estudiar la agenda-setting en cada una de sus manifestaciones, Benton y Fraizier realizaron un sondeo en Estados Unidos con las siguientes preguntas: ¿cuáles son los problemas más importantes del país?, ¿qué soluciones han aplicado los políticos a estos problemas? y "¿por qué está usted en contra o a favor de esas soluciones?. Estas tres cuestiones representan otros tantos niveles de conocimiento, que exigen distinta atención en la recepción de la información. Las personas que sólo hojean la prensa, recordarán únicamente los temas con los que ya estén familiarizados; los que la lean a fondo, serán capaces de retener mejor la información y podrán pronunciarse sobre la efectividad o no de las soluciones planteadas por los medios. Benton y Fraizier advirtieron que en el segundo y el tercer nivel, el influjo más poderoso lo obtiene la prensa, y el más bajo, la televisión, de modo que los ciudadanos recuerdan mejor asuntos que se han tratado por escrito que otros que se han difundido sólo a través de medios audiovisuales.

Estos resultados llevaron a los autores del estudio a la conclusión de que, en niveles más profundos de conocimiento, son los periódicos los que establecen la agenda, tanto de sus lectores como de los telespectadores. Desde esta perspectiva, la televisión no tiene tanta influencia política como se pensaba, si bien es el medio por el que más votantes siguen las campañas electorales.

Asimismo, conviene también resaltar que el grado de influencia de los medios de comunicación varía según el tipo de temas que se aborde. Por ejemplo, los asuntos que las personas no pueden conocer de primera mano y sólo se difunden gracias a los medios (temas unobstrusive, del tipo conflictos bélicos en el extranjero o acuerdos internacionales) son más proclives a los efectos de la "agendasetting" que los que pueden experimentarse de modo directo (temas obstrusive),

\footnotetext{
5 FUNKHOUSER, Ray: "The Issues of the Sixties: An Exploratory Study in the Dinamics of Public Opinion", en Public Opinion Quarterly, núm. 66, 1973, pp. 62-75.

${ }^{6}$ BENTON, Marc y FRAZIER, Paul Jean: "The Agenda-Setting Function of the Mass Media at Three Levels of Information Holding”, en Communication Research, núm. 3, vol. 3, 1976, pp. $261-274$.
} 
caso del precio de la gasolina o de la leche; lo que implica que un mensaje político referido a realidades lejanas tiene mayor efecto en la conciencia de los ciudadanos.

Además, el grado de influencia de los "mass media" también varía según las características sociodemográficas de la población, aunque en este caso el resultado depende del país y del tipo de mensaje. Canel, Llamas y Rey afirman que, generalmente, los ciudadanos con un nivel de formación superior son menos vulnerables a la 'agenda-setting' que los que tienen un menor nivel; la izquierda es más vulnerable que la derecha; las mujeres, más que los hombres ${ }^{7}$.

Por otro lado, también se ha comprobado que los partidos políticos son susceptibles a las agendas de los medios de comunicación, puesto que tienden a guiarse por aquellos temas que éstos consideran de interés, publican o emiten, para elaborar sus mensajes, sus programas electorales o incluir ideas en sus eslóganes y logotipos. Este aspecto fue abordado en su momento por Gormley ${ }^{8}$, quien concluyó que, pese a que la prensa consigue imponer las cuestiones que interesan al público, siguen sin respuesta las preguntas sobre quién establece la agenda de los "mass media" y qué hace que éstos privilegien unos asuntos sobre otros.

La respuesta a estas dos preguntas corresponde a lo que McCombs y Shaw llaman la "cuarta fase de investigación" de la "agenda-setting", en la que se intentan determinar las influencias institucionales que partidos políticos, oficinas de prensa, gobiernos, etcétera, ejercen sobre los medios de comunicación.

De acuerdo con las investigaciones emprendidas en este sentido, la agenda depende de un elevado número de factores: los periodistas, el intento que las instituciones políticas realizan para ocupar espacio en las noticias, los partidos políticos, las agencias de prensa, los gabinetes de comunicación, la competitividad entre las propias empresas periodísticas, el sistema de partidos, las actitudes profesionales de los periodistas y los códigos de objetividad de la información política, e incluso de las presiones de los partidos y las instituciones a los directores de los medios.

Resumiendo, las principales conclusiones a las que han llegado las investigaciones realizadas hasta ahora sobre la canalización temática en los "mass media" serían:

1) Existe una correlación entre la jerarquía de temas establecida por los medios y la jerarquía expresada por los votantes, produciéndose, o bien una influencia de aquéllos sobre éstos, o bien una sensibilidad de las empresas informativas respecto de las preocupaciones de los ciudadanos; o ambos procesos a la vez

7 CANEL, María José; LLAMAS, Juan Pablo; y REY, Federico: "El primer nivel del efecto de la Agenda-Setting en la información local: los problemas más importantes de la ciudad de Pamplona", en Comunicación y Sociedad, vol. IX, núms. 1-2, 1996, p. 25.

${ }^{8}$ GOMLEY, William: "Newspaper Agendas and Political Elites", en Journalism Quarterly, núm. 52, 1975, pp. 304-308. 
2) Los medios de comunicación influyen sobre la percepción que el público tiene sobre cuáles son los asuntos importantes, hecho que suele incrementarse en periodo electoral.

3) Esta influencia de los "media" parece ser mayor por lo que respecta a aquellas cuestiones que difícilmente tendrán un impacto directo en la vida cotidiana de la mayoría de los votantes (temas unosbtrusive). No obstante, también interesan a los receptores de los mensajes de masas los asuntos relacionados con su experiencia directa (temas obstrusive), tales como la economía, el empleo o la sanidad.

4) A veces, para el votante es más fácil captar la imagen de los políticos que su repertorio temático, sobre todo por lo que respecta a los rasgos de personalidad, frente a su aptitud para el cargo. Por ello, existen auténticos catálogos de candidatos clasificados según sus apariciones en los medios de comunicación y los rasgos que éstos subrayan.

5) Los medios contribuyen a la construcción de una realidad de la que luego dependerá la decisión de ir a votar o no y a quién.

6) Todo esto nos lleva a pensar que los medios serían auténticos establecedores de agenda, si se diera el caso de que no se limitaran a reproducir las prioridades y puntos de vista de poderosos proveedores informativos, como los políticos y sus estrategas, ya que a la hora de decidir, la mayoría de los periodistas dedicados a las campañas electorales quedan supeditados a lo que hacen o dicen los candidatos y sus equipos de trabajo, o a lo que las fuentes internas de la política les suministra.

7) Coincidimos, por tanto, con la idea sobre la existencia de valores de preagenda expuesta por Díaz Nosty, según el cual la selección de contenidos, y con ella, las exclusiones; el tratamiento y el relieve informativo; los llamados efectos de rotulación, las medialidades; la modulación, los sesgos constructivos, etc., se ajustan más a las rutinas profesionales y a los procesos de elaboración retórica, que advierten del interés de las audiencias y de cómo interesar a las audiencias, los mecanismos mediáticos de la proxémica, etc., y no olvidan el carácter vicario de esta función ${ }^{9}$; si bien en el caso de los contenidos de las campañas electorales, habría que incluir, dentro de lo que hemos denominado rutina profesional, el comportamiento de la mayoría de los periodistas, que dependen de los actos o las declaraciones de los políticos.

9 DÍAZ NOSTY, Bernardo: Los medios y la hipótesis de la democracia degradada, Servicio de Publicaciones de la Universidad de Málaga, Málaga, 1995, p. 45. 


\section{LA CONSTRUCCIÓN PERIODÍSTICA DE LA REALIDAD POLÍTICA}

"Así son las cosas, y así se las hemos contado". Con esta frase solía cerrar los noticiarios Ernesto Sáez de Buruaga durante su etapa al frente de los servicios informativos de Antena 3 Televisión. Los periodistas tratan de contar cada día las cosas tal y como han sucedido, pero ¿han sido así realmente? Y en el caso de la política, ¿se puede decir que el mensaje que difunden los medios se identifica con la realidad cotidiana de los ciudadanos?

Con la pregunta "¿qué contaremos hoy?" comienzan a diario su trabajo las redacciones de los medios de comunicación de todo el mundo. El espacio (página en prensa y tiempo en radio y televisión) está en blanco. Desde el "momento cero" hasta la publicación de una información, ésta atraviesa un proceso que la mass communication research ha estructurado en tres etapas:

1) "Newsgathering", que consiste en la recogida de la información en bruto. Son los datos que llegan desde las fuentes a través de notas y comunicados, ruedas de prensa, teletipos, llamadas, contactos directos por parte del periodista... Este proceso de recogida de información estará determinado por la infraestructura tecnológica del medio en cuestión (móvil, conexión a Internet, agencias, etcétera), así como por la organización de la redacción.

2) "Newsmaking", que es la fabricación material de la noticia. La información que llega al medio no tiene cabida en su totalidad en el espacio y/o tiempo disponibles, al margen de que no todo su contenido será relevante para la opinión pública, por lo que existe necesidad de seleccionar. Para ello, los criterios que se aplican son muy variados, y van desde la novedad, la actualidad y la proximidad, hasta los rasgos conflictivos o exóticos que presentan los acontecimientos: son los denominados factores de noticiabilidad. Además, esta selección puede estar sometida a presiones por parte de los propietarios del medio, los anunciantes o las autoridades políticas.

3) 'Newsreporting', que es el proceso de comunicación de la noticia. Una vez que se ha decidido qué se difundirá y se ha tratado convenientemente la información para que esté en condiciones de ocupar su espacio informativo, se la dota de todos los elementos que caracterizan al discurso del medio: titular, fotografía de acompañamiento y ubicación, en el caso de la prensa escrita; edición de las imágenes, en el de la televisión; infografías animadas, para los medios telemáticos; etcétera.

En cada una de estas fases por las que pasa la información hasta llegar a ser noticia, se toman una serie de decisiones, sobre el tipo de fuente a la que se va a acudir para recoger la información, qué periodista de la redacción cubrirá la 
noticia, en qué sección se ubicará, qué genero informativo se utilizará, el espacio que ocupará... Este proceso recibe el nombre de "gatekeeping".

Paula Shoemaker clasifica los factores que pueden intervenir en el proceso de elaboración de la noticia en los medios de comunicación en cuatro niveles de mediación $^{10}$ : las características individuales de los periodistas, la organización de las redacciones, las rutinas profesionales y los factores externos (fuentes, autoridades políticas, inversión publicitaria y otros medios de comunicación).

Veamos con detalles cada uno de ellos:

1) Las características individuales de los periodistas: su formación académica, su experiencia, su comportamiento ético; las aptitudes personales, valores y creencias que presenten, así como sus tendencias políticas. Todos estos elementos pueden influir en el tratamiento que el profesional de los medios da a las informaciones que llegan a una redacción.

2) Las rutinas profesionales. Aquellas prácticas o usos que se repiten con frecuencia en el quehacer informativo y que constituyen el contexto inmediato en el que se desenvuelven los periodistas. Son rutinas profesionales responder al quién, el cómo, el qué, el por qué y el cuándo de un acontecimiento; o rechazar las noticias que no estén lo suficientemente contrastadas. Este tipo de prácticas son muy importantes en el "gatekeeping".

3) Cuestiones organizacionales. Es la influencia que ejerce sobre la información todo lo que tiene que ver con la infraestructura del medio: organización personal, distribución de las secciones, condiciones tecnológicas, suscripción a una o varias agencias de noticias, identidad propia de la redacción, propiedad del medio...

4) Elementos externos al medio: Entre otros:

- Las fuentes: pueden ser convencionales (rueda de prensa, nota de prensa, ceremonias, informes, archivos) o informales (filtraciones, testigos presenciales exclusivos, actas no gubernamentales, etcétera).

- Otros medios de comunicación. Editores de prensa y realizadores de radio y televisión están siempre atentos a lo que hace la competencia.

- La publicidad.

- Los gobiernos.

- La audiencia.

${ }^{10}$ SHOEMAKER, Pamela: Gatekeeping, Sage, Londres-Newbury Park-Nueva Delhi, 1991. 
Si todo esto es así, si el proceso de elaboración de la información implica mucho más que una función de selección, se puede decir que el mensaje político que llega desde las instituciones o los partidos políticos sufre una transformación severa al ser recogido por los medios de comunicación. De hecho, de una misma realidad política se obtienen relatos diferentes según cuál sea el medio que la aborde. Es lo que ha llevado a Davis ${ }^{11}$ a contraponer la "teoría del prisma" a la del "espejo": los medios no reflejarían la realidad tal cual es, sino que actuarían como un prisma que recibe rayos de luz -informaciones de toda procedencia- y los refracta, constriñe y expande. De esta forma, los medios encuadran, enfocan, transforman e incluso inventan en ocasiones la actualidad sobre la que deben informar.

\section{LOS MENSAJES ELECTORALES}

Una vez que los expertos en estrategia de los partidos políticos que concurren a unas elecciones conocen a los destinatarios de sus mensajes, y han analizado los puntos débiles y fuertes del candidato y de sus adversarios, lo que procede es encontrar las ideas que constituyan los ejes de la campaña. Se trata de un momento crucial, en el que todos los datos de la investigación realizada en una primera fase de análisis de la situación se unen al conocimiento y la experiencia de los asesores, para crear el mensaje: es el "Santo Grial de la estrategia electoral", la misión más difícil, porque "una cosa es conocer las preocupaciones y problemas de la gente, y otra bastante distinta, ser capaz de articularlas de manera creíble y aceptable para esa gente" ${ }^{, 12}$.

Para Martín Salgado, un mensaje político eficaz ha de responder a tres preguntas básicas:

— ¿Por qué quiere un candidato que lo elijan?

- ¿Por qué representa una opción mejor que la de sus adversarios?

- ¿Qué políticas llevará a cabo?

Contestadas estas preguntas, existen muchas maneras de expresar la idea central que se quiere transmitir: imágenes, palabras, eslóganes, discursos, medios audiovisuales, etcétera. Lo que sí es necesario es que, independientemente del canal que se elija, se comunique de manera clara.

Los factores que condicionan el mensaje son tres: el candidato, el electorado y el contexto (al contrario de lo que se pueda pensar, los estrategas desempeñan aquí un papel secundario):

${ }^{11}$ DAVIS, Richard: The Press and American Politics. The New Mediator, Longman, Nueva York, 1992.

12 MARTín SALGADO, Lourdes: Marketing político. Arte y ciencia de la persuasión de la democracia, Ariel, Barcelona, 2002, p. 45. 
1) El candidato o la candidata: sus cualidades y defectos.

2) El electorado: sus preferencias $y$, sobre todo, sus preocupaciones.

3) El contexto: el tiempo y el lugar en que se celebra la elección.

En ciertas ocasiones, se suele añadir un cuarto factor, los medios de comunicación, a los que se considera responsables de la formación de la agenda de campaña, pero lo cierto es que los temas abordados por los medios parten principalmente de los tres factores que acabamos de enumerar.

El cometido de los profesionales de la comunicación política es el de saber incorporar a la agenda de los periodistas determinados asuntos, cuando el electorado parezca interesado en ellos, y en especial, cuando dichos temas favorezcan a la candidatura, o bien sean parte ineludible del contexto.

Las características de los candidatos, las preocupaciones de los electores y el entorno constituyen lo que Aristóteles denominó "atechnoi", hechos y acontecimientos que quedan fuera del alcance del comunicador.

Por lo general, en una campaña electoral se suelen dar cuatro tipos de mensajes a la audiencia:

a) Mensajes que hablan de los candidatos:

Pueden consistir en juicios sobre su labor pública anterior a las elecciones o en revelaciones sobre su vida privada.

b) Mensajes demandados por el elector:

Los temas más importantes suelen tener su origen en los votantes. La clave de la estrategia del político está por lo general en conocer y entender lo que necesita el elector. De lo que se trata es de ofrecerles un producto que aporte soluciones. En este sentido, los partidos y con bastante frecuencia los medios de comunicación encargan encuestas que determinarán cuáles son las principales preocupaciones de los votantes, para poder referirse a ellas en la campaña. Entre las principales cuestiones que suelen acaparar la atención de la ciudadanía se encuentran:

- La economía, en especial la doméstica.

- Los asuntos relacionados con el bienestar: sanidad, educación y seguridad.

En tiempos de paz, estos suelen ser los dos grandes bloques de asuntos a tratar en el marco de una campaña electoral.

c) Mensajes relacionados con el contexto

Es un elemento primordial que hay que tener en cuenta cuando nos movemos en el ámbito de la retórica y la persuasión. Así, el conflicto de Irak (factor contextual) tuvo un papel relevante en España durante las últimas elecciones 
municipales -mayo de 2003-y las generales de marzo de 2004; como lo tuvieron la guerra del Vietnam o la lucha por los derechos civiles en los Estados Unidos en la década de los sesenta, o el escándalo Watergate, en el mismo país, a comienzos de la década siguiente.

El peso de los temas clave varía en función del contexto de cada elección; por ejemplo, en periodos de recesión, hablar de economía es inevitable. Lo más usual es que exista una conexión entre el entorno y las preocupaciones del votante, si bien no siempre ocurre así: en Estados Unidos, la seguridad y el crimen son cuestiones electorales fundamentales, pese a que su incidencia en la vida diaria del ciudadano ha disminuido.

d) El análisis de la gestión del Gobierno

En toda campaña electoral hay siempre un candidato que habla de la gestión realizada por el equipo de gobierno, de un cambio o de la experiencia, de lo conocido o de lo que está por venir. En realidad, cualquier elección puede ser considerada un referéndum para evaluar al partido o dirigente gobernante.

Para determinar si se debe utilizar el marco de la gestión, los consultores suelen fijarse en los indicadores económicos del momento y en la popularidad de los gobernantes, especialmente del presidente. Si la gestión de éstos se considera satisfactoria y recibe la aprobación de la mayoría de los ciudadanos, la campaña debe consistir, para el partido en el poder, en un recordatorio de lo que se ha hecho. Cuando ocurre lo contrario, el mensaje de la oposición debe ser el de ofrecer a los votantes un recambio atractivo frente a sus actuales gobernantes.

La idea básica en estos casos es que un buen mandato merece otro. Cuando un gobernante goza de popularidad, su carrera electoral es casi un desfile, una ocasión para recordar lo que ha hecho y lo bien que marchan las cosas; más que plantear una campaña interesante, interesa dormir la campaña. Los temas dominantes de un partido en el poder deben ser "seguir por el buen camino" o "continuar la labor iniciada."

Por el contrario, cuando las cosas van bien pero el ciudadano no las percibe, no es conveniente hacer hincapié exclusivamente en los mensajes positivos. Por ejemplo, no es recomendable decir que la economía marcha viento en popa si tal bonanza no es percibida aún por el ciudadano. Otra estrategia habitual es hacer que el candidato en el poder aparezca en los medios actuando como presidente, pues los símbolos que rodean al cargo denotan fuerza, autoridad y experiencia.

Pero dicha experiencia puede funcionar como un arma de doble filo. Disfrutar del look presidencial tiene indudables ventajas en términos persuasivos (fotos en el despacho, encuentros con mandatarios extranjeros, etcétera); pero si la legislatura es percibida como un fracaso, las imágenes presidenciales de un candidato resultarán contraproducentes. Cuando las cosas no han ido bien, un político debe 
realizar dos campañas: una contra su adversario y otra contra su labor pasada, y la segunda será más difícil que la primera.

Otro asunto que no suele faltar en una campaña electoral es el del "cambio", que es la reivindicación por excelencia de la oposición: lo nuevo es el adjetivo principal del programa de cualquier candidato opositor. En unas ocasiones, se identifica el cambio con políticas concretas, y en otras, con determinadas personas. En realidad, la estrategia es la del contraste. Una técnica muy utilizada por los gobiernos para contrarrestar esta idea-fuerza es apelar al miedo ante lo desconocido o al riesgo e incertidumbre que implica cualquier cambio.

Cuando el gobernante no ha cosechado demasiados éxitos durante su etapa ejecutiva inmediatamente anterior a las elecciones, el cambio se convierte en leitmotiv de su campaña. Y lo cierto es que la experiencia nos indica que el votante perdona, pero no vota de nuevo a un candidato que le ha defraudado.

\section{ANÁLISIS DE LA CAMPAÑA CORRESPONDIENTE A LAS ELECCIO- NES GENERALES DE 2004}

Como manifestación empírica de todo lo expuesto hasta aquí, vamos a abordar a continuación los temas que gozaron de mayor peso en la campaña de las pasadas elecciones generales españolas (marzo de 2004), y su relación -o falta de ella- con los asuntos demandados por los electores; es decir, vamos a confrontar la agenda de los medios y la agenda del público, en un escenario geográfico concreto: la provincia de Málaga.

Para ello, recurriremos a los sondeos de contenido electoral realizados por el Centro de Investigaciones Sociológicas (CIS) y por diversos diarios malagueños, en combinación con una base de datos de las noticias aparecidas en los medios de comunicación de la provincia seleccionada durante las seis semanas anteriores al 14-M, compuesta por 350 registros articulados en más de 20 campos de estudio.

De acuerdo con el barómetro del CIS correspondiente a febrero de $2004^{13}$, es decir, cuando sólo faltaba un mes para las generales, los españoles consideraban que los principales problemas del país eran el paro (un 65 por ciento), el terrorismo (un 43,2 por ciento), la inseguridad ciudadana (un 22,9 por ciento) y la vivienda $(21,8$ por ciento). Por otro lado, los problemas que más afectaban de manera directa a los individuos encuestados eran el paro (37 por ciento), la vivienda (20,5 por ciento), los problemas económicos (17,5 por ciento) y la inseguridad ciudadana (15,6 por ciento). Por lo tanto, estos temas se presentaban a priori como ideas-fuerza de la campaña electoral.

En estas elecciones, el Partido Popular hizo hincapié sobre todo en los frutos de su acción de gobierno durante los últimos ocho años. Basó sus eslóganes en

${ }^{13}$ Disponible en http://www.cis.es/cis/opencms/ES/2 barometros/depositados.jsp. 
El control de la agenda mediática en campaña electoral...

la buena marcha del país, el intenso ritmo de creación de empleo y el crecimiento económico que permitía incrementar los niveles de bienestar de los españoles. Los estrategas populares estaban convencidos de que el electorado optaría por la estabilidad y por las políticas desarrolladas desde 1996 por el Ejecutivo de José María Aznar.

Los socialistas, por su parte, se dedicaron a denunciar la inaccesibilidad de la vivienda, la precariedad del empleo, la inseguridad en las calles y el deterioro que estaba sufriendo la democracia en España. Del candidato popular, Mariano Rajoy, los socialistas denunciaron de manera reiterada que no se atrevía a enfrentarse públicamente a su adversario, pues rechazó al debate televisivo cara a cara con Rodríguez Zapatero; también criticaron la cobertura de la campaña efectuada por la radiotelevisión pública estatal (RTVE). El equipo del PSOE estaba convencido, y en este sentido articuló uno de sus mensajes fundamentales, de que Rodríguez Zapatero sería presidente del Gobierno el 14 de marzo.

Por último, Izquierda Unida (IU), eligió como tema principal de su campaña las políticas sociales, un aspecto en el que consideraban que la gestión popular había resultado un completo fracaso. Al mismo tiempo, Llamazares y los suyos insistieron en que fueron los populares los que desencadenaron el peligro de disgregación territorial del país. La vivienda fue uno de los temas fuertes de IU, junto con la propuesta de subida del salario mínimo hasta los 660 euros, a lo que sumaron un buen número de propuestas de orientación ecologista.

Si establecemos una comparación entre los asuntos que, según los sondeos, estaban llamados a ser centro del debate durante la campaña electoral, y los que finalmente ocuparon la agenda de los medios, llegamos a la conclusión de que existe bastante similitud entre ambos bloques, con alguna que otra excepción.

Durante el mes de febrero, las cuestiones que mayor presencia tuvieron en los medios fueron las promesas de mejora de las infraestructuras o la demanda de las mismas, la lucha contra el desempleo, la vivienda y la seguridad, a los que se añadieron algunos asuntos relacionados con el bienestar, como la educación, la salud o las políticas destinadas a la mujer.

Pero, como era de esperar, los temas impuestos por el contexto irrumpieron en la campaña desde el principio, ocupando gran parte de la agenda de los medios de comunicación, unas veces por las continuas filtraciones interesadas, y otras veces por los incidentes que habían acontecido antes de la campaña, durante la legislatura o incluso durante la campaña electoral.

Así, cuestiones como la reunión de Josep Lluís Carod-Rovira con representantes de ETA en Perpiñán, la guerra de Irak, el plan soberanista del gobierno autónomo vasco, los futuros pactos postelectorales, el desastre del Prestige y el del Yak-42, la gestión del tripartito catalán, la unidad de España, las crisis del PSOE o la ausencia de debates entre los candidatos, coparon gran parte del espacio mediático durante el desarrollo de la campaña electoral. 
De esta manera, los temas relacionados con el contexto ocuparon casi un 24,4 por ciento del espacio de los medios, mientras que los asuntos demandados por el elector acaparan un 51,9 por ciento de la cobertura, frente al 10 por ciento que obtuvieron las cuestiones relacionadas con los candidatos, su labor o su vida privada. Por último, un 21,2 por ciento lo ocupó el análisis de la gestión realizada por el Gobierno y la conveniencia o no de un cambio en el Ejecutivo. Evidentemente, estos datos se refieren al contenido difundido por los medios hasta el 11 de marzo, ya que a partir de este momento, la información política electoral o institucional relacionada con el contexto se incrementó a consecuencia de los atentados terroristas de Madrid y la catarata de acontecimientos que se sucedieron en las 72 horas posteriores.

En cuanto al origen de las noticias, cabe señalar que los partidos prefirieron los denominados encuentros directos con los electores, especialmente con públicos específicos y por sectores, para realizar sus propuestas o anunciar sus medidas, tal y como quedó recogido en los medios impresos; mientras que para criticar a los adversarios y hacer balances de gestión optaron por el tradicional mitin.

\section{CONCLUSIÓN}

Todo lo expuesto en el apartado anterior viene a ratificar las ideas con que abríamos este trabajo, en torno a la "agenda-setting". Los periodistas marcan la pauta de los temas sobre los que el ciudadano hablará u opinará en campaña electoral; ahora bien, no queda tan claro, tal y como indicábamos anteriormente, quién define estas cuestiones: ¿son los medios o los partidos?

En el caso de la campaña electoral previa a las elecciones del 14-M, los datos apuntan a que fueron los partidos políticos quienes definieron el contenido de los mensajes destinados a los votantes y, por tanto, de la agenda informativa de los medios. Luego, en cierta forma, la balanza en la pregunta anterior se inclinaría del lado de los propios partidos, en detrimento de los mass media. No obstante, es cierto que en algunas ocasiones lo difundido primero por la prensa fue convertido luego en materia de debate electoral, en especial a partir de los atentados del 11$\mathrm{M}$, pero esto podría no ser más que una anomalía provocada por lo excepcional (y trágico) del contexto. 


\section{BIBLIOGRAFÍA COMPLEMENTARIA:}

ARCEO VACAS, José Luis: Campañas electorales y publicidad política en España (1976-1991), PPU, Barcelona, 1993.

BELL, Daniel: El fin de las ideologías: sobre el agotamiento de ideas políticas en los años 50, Ministerio de Trabajo y Asuntos Sociales, Madrid, 1992.

BERROCAL, Salomé: Comunicación política en televisión y nuevos medios, Ariel, Barcelona, 2003.

GÓMEZ CALDERÓN, Bernardo: "Retos, debilidades y fortalezas del periodismo político en España", en VV. AA.: La Universidad y nuestros mayores, Servicio de Publicaciones de la Universidad de Málaga, Málaga, 2005.

LOZANO RENDÓN, Juan Carlos: "La espectacularización en las elecciones mexicanas de 2000", en Revista Mexicana de Comunicación núm. 14 (71), julio-agosto de 2001, pp. 34-37.

McGUINNISS, Joe: Cómo se vende un presidente, Península, Madrid, 1970.

MUÑOZ-ALONSO, Alejandro: "La democracia mediática", en MUÑOZ-ALONSO, Alejandro y ROSPIR ZABALA, Ignacio (coords.): Democracia mediática y campañas electorales, Ariel, Barcelona, 1999.

PANIAGUA ROJANO, Francisco Javier: Comunicación política electoral. Elecciones autonómicas de Andalucía en 2000, Servicio de Publicaciones de la Universidad de Málaga, Málaga, 2004.

RAMONET, Ignacio: Un mundo sin rumbo. Crisis de fin de siglo, Temas de Debate, Madrid, 1997.

SCHWARTZENBER, Roger-Gérard: El show político. Ensayo sobre y contra el starsystem en política, Dopesa, Barcelona, 1978.

TREJO DELARBE, Raúl: "El imperio del marketing político. Cuando las imágenes desplazan a las ideas", en América Latina Hoy, núm. 25, agosto de 2000, pp. 25-22.

WEBER, Max: El político y el científico, Alianza Editorial, Madrid, 1967.

(Recibido el 5-05-06, aceptado el 24-06-06) 